Article

\title{
Chemical Characterization of an Encapsulated Red Wine Powder and Its Effects on Neuronal Cells
}

\author{
Diego Rocha-Parra ${ }^{1,2,3}$, Jorge Chirife ${ }^{1}$, Clara Zamora ${ }^{1,2}$ and Sonia de Pascual-Teresa ${ }^{3, *}$ \\ 1 Faculty of Engineering and Agricultural Sciences, Pontifical Catholic University of Argentina, \\ Buenos Aires C1107AAZ, Argentina; diegofer2484@gmail.com (D.R.-P.); jchirife@gmail.com (J.C.); \\ zamoramariacl@gmail.com (C.Z.) \\ 2 National Scientific and Technical Research Council (CONICET), Buenos Aires C1425FQB, Argentina \\ 3 Department of Metabolism and Nutrition, Institute of Food Science, Technology and Nutrition (ICTAN), \\ Spanish National Research Council (CSIC), E-28040 Madrid, Spain \\ * Correspondence: s.depascualteresa@csic.es; Tel.: +34-91-549-2300
}

Academic Editor: Fabio Galvano

Received: 14 March 2018; Accepted: 23 March 2018; Published: 7 April 2018

\begin{abstract}
Red wine polyphenols are known for their implications for human health protection, although they suffer from high instability. For this reason, a red wine powder was prepared by freeze-drying encapsulation in maltodextrin/arabic gum matrix, and its composition was determined by means of high-performance liquid chromatography coupled quadrupole time-of-flight mass spectrometry (HPLC-MS-QTOF). More than thirty polyphenols, including anthocyanins, flavanols, flavonols, phenolic acids and stilbenoids, were identified. Some of the main quantified polyphenols were: malvidin-3-O-glucoside, malvidin 3-O-(6"-acetyl-glucose), petunidin-3-O-glucoside, quercetin-3-O-glucuronide, syringenin-3-O-glucoside, epicatechin, gallic acid and syringic acid. The biological activity of this de-alcoholized and encapsulated red wine on human neuroblastoma SH-SY5Y cells was studied. The results showed that the encapsulated red wine powder has active redox properties, as verified by performing reactive oxygen species (ROS) analysis utilizing a neuronal model. This could help explain its action against the neurotoxicity induced by 6-hydroxydopamine (6-OHDA).
\end{abstract}

Keywords: wine; polyphenol; encapsulation; HPLC-MS-QTOF; cell culture; neuronal; antioxidant

\section{Introduction}

Polyphenols are secondary plant metabolites with diverse physiological functions in the plant, such as ultraviolet protection, attraction of pollinators, anti-parasite functions, and antioxidant protection [1]. Polyphenols are a complex group of compounds, and their analysis and identification has been addressed by several scientists by means of HPLC and UPLC-PDA-Q/TOF-MS in order to overcome this complexity [2,3]. In humans, polyphenols exert important functions through the activation of cellular antioxidant enzymes and signaling pathways [1,4].

Red wine polyphenols have historically been considered potent antioxidants, with a number of benefits for human health [5-7]. The available epidemiological studies suggest that moderate consumption of red wine is associated with a reduction in the risk of cardiovascular disease and carcinogenesis [8]. Regular and moderate red wine consumption is a frequently invoked factor for explaining the low incidence of cardiovascular events in France (known as "the French paradox") compared with other industrialized countries [9-12].

Red wine polyphenols have vasorelaxant effects, which are associated with lower blood pressure [13]. Red wine, de-alcoholized red wine, and grape juice consumption have been shown 
to lower blood pressure in patients with coronary artery disease or hypertension [14,15]. These data suggest that polyphenols, rather than alcohol, are responsible for the vasorelaxant benefits.

With the current evidence on the biological value of red wine polyphenols and the deleterious effect of ethanol, a new interest has grown in the possibility of producing non-alcoholic wine extracts that nevertheless contain its polyphenols. It has been shown that the removal of ethanol from red wine has little impact on its beneficial health properties; namely, its antioxidant effects and protection against cardiovascular diseases [16,17]. One physical procedure to remove alcohol (and also water) is through wine dehydration, which leads to a concentrated wine dry extract containing its polyphenols. Freeze-drying has been proved to be the most suitable method for drying thermosensitive substances, minimizing thermal degradation reactions [18-20].

The biological activity of red wine polyphenols has been determined in some cell lines; however, only a few studies have been carried out on the effect of polyphenols on the nervous system or in neuronal cells [21]. In most of these studies, only isolated red wine polyphenols (mainly resveratrol) were studied. This approach ignores some studies suggesting that the health benefits attributed to wine polyphenols are due to their joint action rather than the action of individual compounds [22]. Furthermore, the complexity of the polyphenolic constituents of red wines makes it difficult to separate the specific contribution of each phenolic compound and cannot mimic the natural and balanced mixture of the hundreds of phenolic compounds present in red wine.

A de-alcoholized wine powder (WP) obtained via freeze drying (using suitable encapsulants), may serve to measure the biological effects of red wine polyphenols on cells, avoiding the presence of alcohol while maintaining the complex composition of red wine.

The purpose of this work was to determine, (a) the chemical composition of phenolics in the WP using high performance liquid chromatography coupled with high resolution Q-TOF mass spectrometry (HPLC-MS-QTOF), and (b) the biological activity of this dealcoholized wine powder on a human neuronal cell model.

\section{Results}

It has been previously determined that the WP used in this study is a free flowing de-alcoholized product (less than 1\% residual alcohol) with good solubility in cold water that is easy to handle, shelf-stable (due to of its low water activity 0.11 ) and can be integrated as an ingredient in different food systems $[18,19]$. Figure 1 shows a picture of the WP. It has a total polyphenol concentration (Folin's method) of $986 \mathrm{mg}$ GAE/100 g powder (GAE, gallic acid equivalent) [23]. The increased polyphenol concentration (several times higher as compared to liquid red wine) resulted from the balance between water and alcohol elimination and $\mathrm{MD}_{10} /$ gum Arabic gum incorporation.

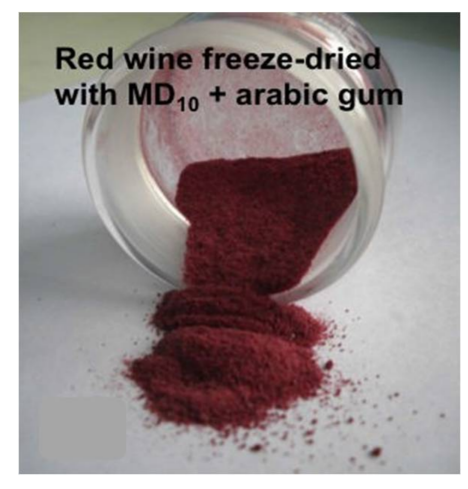

Figure 1. De-alcoholized freeze-dried red wine powder.

The retention of total polyphenols after lyophilization/encapsulation of the liquid red wine was approximately $98 \%$ [18]. This agrees with the well-known fact that freeze-drying is a gentle method that is not expected to degrade polyphenols. During the freeze-drying of the present red wine, the 
maximum temperature in the sample was kept below $24^{\circ} \mathrm{C}$, which, in addition to the low partial pressure of oxygen (due to vacuum in the drying chamber), minimizes the oxidation of polyphenols. Some authors have determined the stability of several polyphenols in wine powder stored under accelerated storage conditions $[19,20]$. It is of note that due to its low water activity $\left(\mathrm{a}_{\mathrm{w}}\right.$ below 0.25$)$, this WP was microbiologically stable at room temperature.

\subsection{Red Wine Powder (WP) Polyphenolic Composition}

Although some results on the composition of this encapsulated red wine have already been presented in the literature $[19,20]$, a more complete characterization, as performed here, has not yet been made. Samples were prepared at a concentration of $50 \mathrm{mg} / \mathrm{mL}$ for their analysis by HPLC-QTOF. Analyses were done by using electrospray ionization (ESI) in the positive and negative mode. Thirty-five polyphenols, including anthocyanins, flavanols, flavonols, phenolic acids and stilbenoids were determined in the WP, as shown in Table 1. Malvidin-3-O-glucoside was the main compound in the anthocyanin group, while quercetin-3-O-glucuronide, epicatechin, gallic acid and piceid were the main compounds within Flavonols, Flavanols, Phenolic acids and Stilbenoids, respectively.

Figure 2 shows, as an example, the Ultraviolet-visible (UV-Vis) chromatogram at $360 \mathrm{~nm}$ and extracted ion chromatograms (EIC) of the mass spectrometry (QTOF-MS) analysis in the positive mode for ions 479.0817 and 509.1020 (left) and the tandem mass spectrometry $\left(\mathrm{MS}^{2}\right)$ spectra of the two peaks corresponding to Quercetin-3-O-glucuonide and Syringenin-3-O-glucoside (right). Anthocyanins represented $80 \%$ of polyphenols quantified in the present analysis (Table 1 ). At $280 \mathrm{~nm}$, one of the main peaks was identified in the negative mode as being gallic acid. Syringic acid and caffeic acid were also present in the WP, together with resveratrol and its glucoside, the piceid.
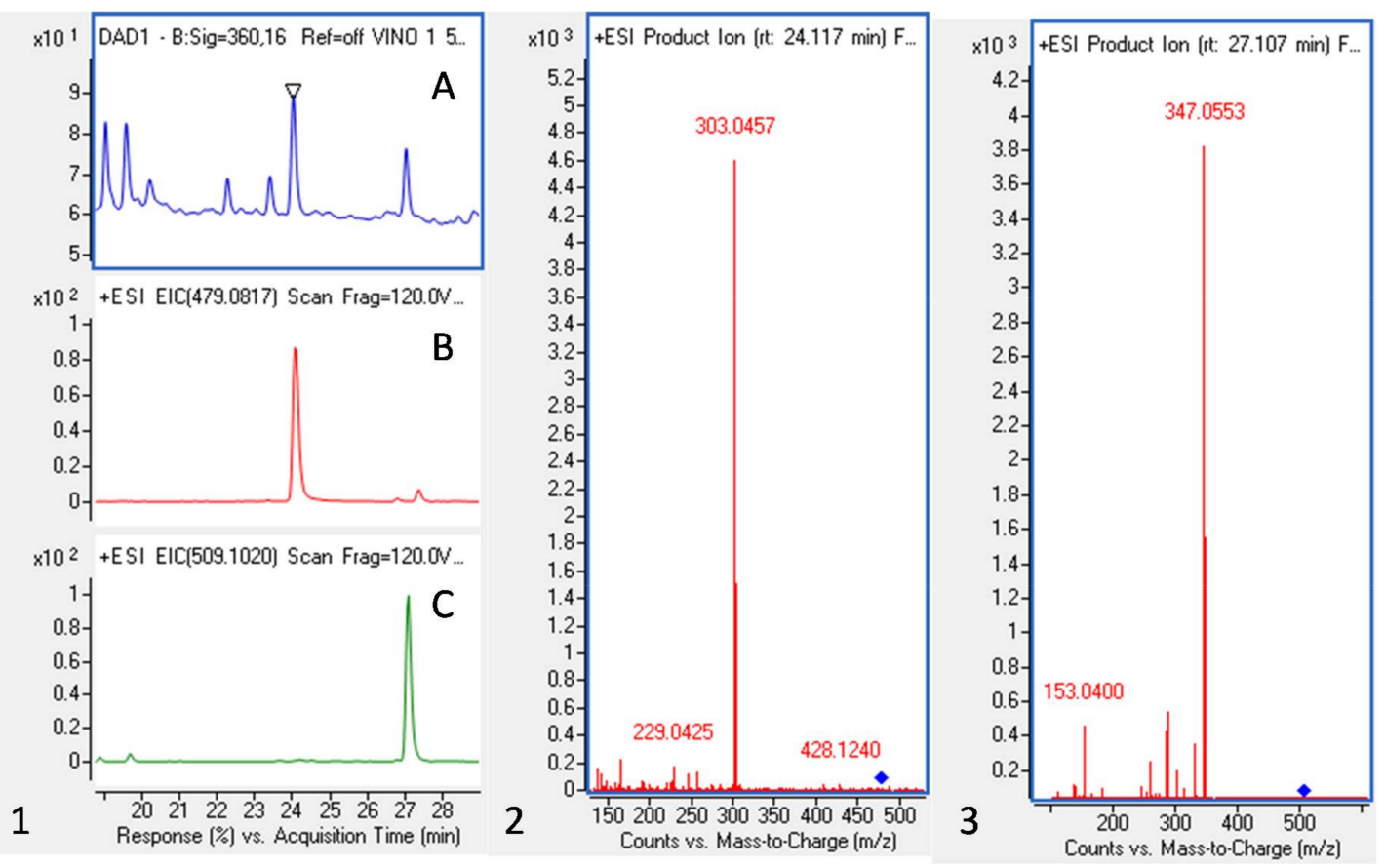

Figure 2. Ultraviolet-visible (UV-Vis) chromatogram (360 nm), extracted ion chromatograms (EIC) and $\mathrm{MS}^{2}$ spectra of two WP flavonols (quercetin-3-O-glucuronide and syrengenin-3-O-glucoside). 1-Chromatograms at 360nm (A), EIC at 479.0817 (B) and 509.1020 (C); 2-MS² spectrum corresponding to the peak at MS+ 479.0817 with a retention time (Rt) of 24.1 and 2-MS ${ }^{2}$ spectrum corresponding to the peak at MS+ 509.1020 with a Rt of 27.0 (see Table 1 for identifications). 
Table 1. Polyphenols present in encapsulated WP as identified by HPLC-QTOF.

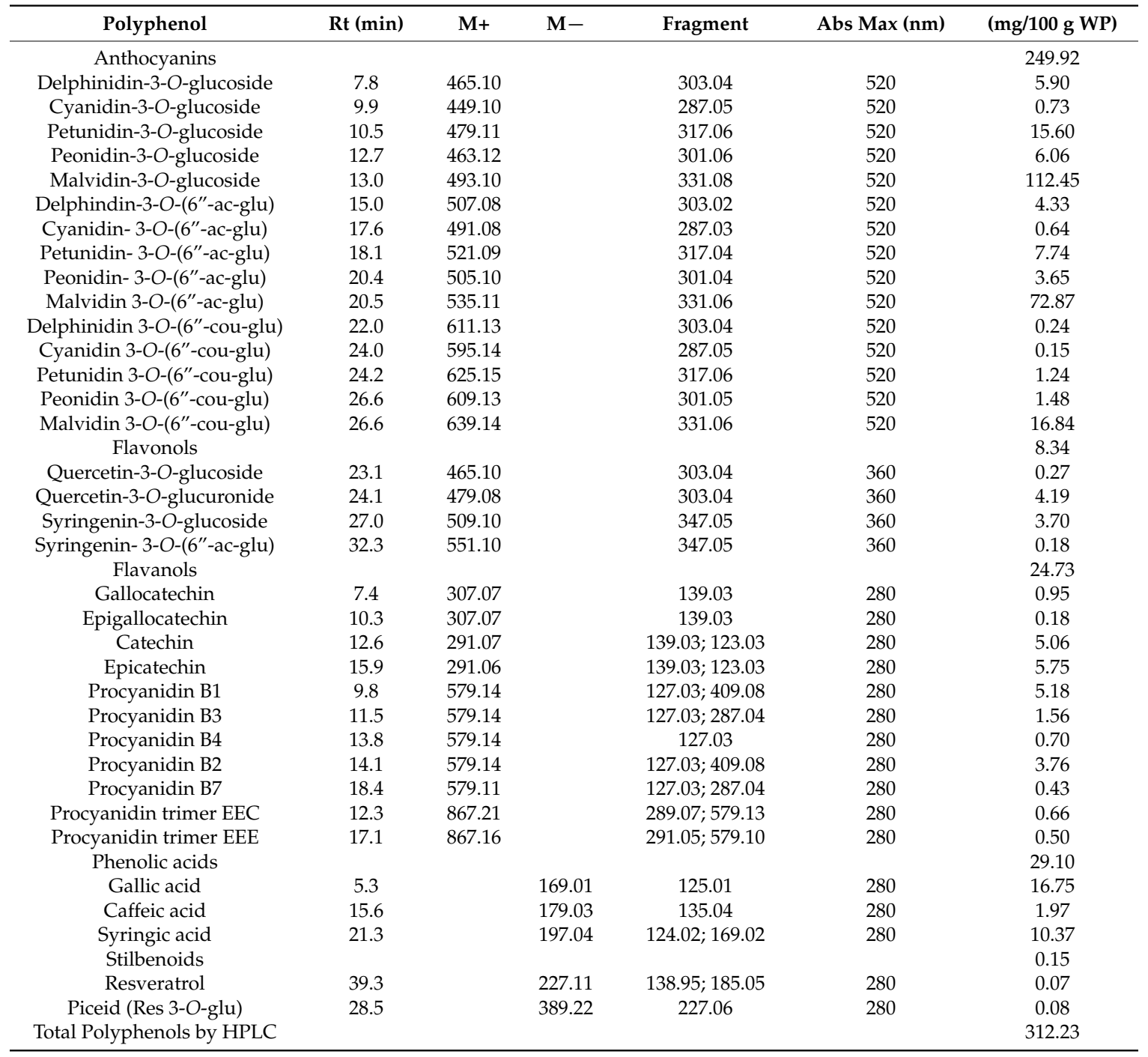

Abbreviations: ac (acetyl), glu (glucose), B1 (epicatechin-( $4 \beta \rightarrow 8)$-catechin), B3 (catechin- $(4 \beta \rightarrow 8)$-catechin), B4 (catechin- $(4 \beta \rightarrow 8)$-epicatechin), B2 (epicatechin-( $4 \beta \rightarrow 8)$-epicatechin), B7 (epicatechin-( $4 \beta \rightarrow 6)$-catechin), EEC (epicatechin-( $4 \beta \rightarrow 8)$ epicatechin-( $4 \beta \rightarrow 8)$-catechin), EEE (epicatechin-( $4 \beta \rightarrow 8)$ epicatechin-( $4 \beta \rightarrow 8)$-epicatechin), Res (Resveratrol).

\subsection{Cell Viability}

In our study, it was found that pre-treatment of SH-SY5Y neuroblastoma cells with up to $200 \mu \mathrm{g} / \mathrm{mL}$ of WP and up to $200 \mu \mathrm{M}$ of (-)-epicatechin did not affect cell viability. It was also verified that none of the encapsulating agents in $\mathrm{WP}\left(\mathrm{MD}_{10}\right.$ and Arabic gum) had a significant effect on cell viability.

To determine an appropriate dose of 6-hydroxydopamine (6-OHDA) treatment on SH-SY5Y cells, a dose-response curve was prepared. This resulted in a dose-dependent decrease in cell viability between $100 \mu \mathrm{M}$ and $250 \mu \mathrm{M}$ (from $100 \%$ to $37.8 \%$ respectively). Since $150 \mu \mathrm{M}$ of 6-OHDA caused a decrease to about a half in cell viability $(61.5 \%)$, this dose was used in the following studies to study the protective effect of WP and (-)epicatechin on 6-OHDA-induced cell damage.

To determine the protective effects of WP and (-)-epicatechin on SH-SY5Y co-incubated with 6-OHDA, a cell viability assay was performed. The (3-(4,5-dimethylthiazol-2-yl)-2,5diphenyltetrazolium bromide) tetrazolium (MTT) assay showed that the cell viability of untreated SH-SY5Y cells was decreased after 6-OHDA activation $(57.1 \%$ of viability with respect to the control 
cells). However, the viability decrease was significantly reversed $(p<0.05)$ on SH-SY5Y when 6-OHDA was incubated with 150 and $200 \mu \mathrm{g} / \mathrm{mL}$ of WP, obtaining $88.3 \%$ and $73.3 \%$ of remaining surviving cells, respectively (Figure 3). On the other hand, cells co-incubated with 50 and $100 \mu \mathrm{g} / \mathrm{mL}$ of WP and 6-OHDA did not show any significant increase in SH-SY5Y viability $(68.6 \%$ and $71.8 \%$ of cell viability respectively).

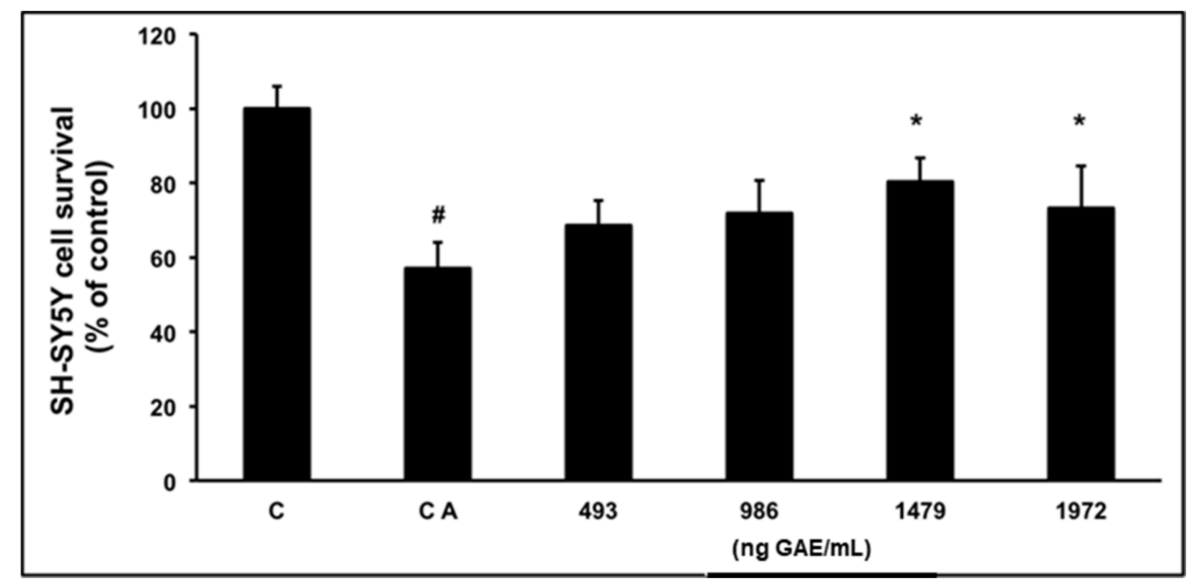

Figure 3. Protective effect of WP against 6-OHDA cytotoxicity in SH-SY5Y cells. SH-SY5Y cells were exposed to 6-OHDA $(150 \mu \mathrm{M})$ in the presence of increasing concentrations of WP (from 50 to $200 \mu \mathrm{g} / \mathrm{mL}$ ) corresponding to 494 to $1972 \mathrm{ng} \mathrm{GAE} / \mathrm{mL}$. Concentrations were expressed as ng gallic acid equivalent (GAE)/mL (9.86 ng GAE/ $\mu \mathrm{g} \mathrm{WP})$. The control activated (CA) and control (C) bars mean that the cells were treated with and without 6-OHDA. The results are expressed as percentage of control and are represented by mean $\pm \mathrm{SD}(n=3)$. ${ }^{\#} p<0.05$ compared to the $(\mathrm{C})$ group and ${ }^{*} p<0.05$ compared to the (CA) group.

In the case of (-)-epicatechin, the results indicated that this compound (in a range of concentrations between 10 and $200 \mu \mathrm{M}$ ) significantly increased the cell survival rate to $81 \%$ and $102 \%$ (Table 2) compared to the activated control treated with 6-OHDA. These results indicate that WP and (-)-epicatechin are effective for the prevention of 6-OHDA-induced SH-SY5Y cell damage.

Table 2. Protective effect of (-)-epicatechin against 6-OHDA cytotoxicity in SH-SY5Y cells. SH-SY5Y cells were exposed to 6-OHDA $(150 \mu \mathrm{M})$ in the presence of increasing concentrations of (-)-epicatechin (from 10 to $200 \mu \mathrm{M}$ ). The results are expressed as percentage of non-treated control and are represented by mean $\pm \operatorname{SD}(n=3) .{ }^{*} p<0.05$ compared to the control activated. Activated control were treated with only 6-OHDA $(150 \mu \mathrm{M})$.

\begin{tabular}{cc}
\hline (-)-epicatechin $(\mu \mathbf{M})$ & SH-SY5Y Cell Survival * $\%$ of Control) \\
\hline Activated Control & $58.0 \pm 5.5$ \\
10 & $81.1 \pm 6.5^{*}$ \\
25 & $96.5 \pm 4.8^{*}$ \\
50 & $99.4 \pm 9.5^{*}$ \\
100 & $89.2 \pm 10.9^{*}$ \\
200 & $102.8 \pm 6.3^{*}$ \\
\hline
\end{tabular}

\subsection{Effect of WP on ROS Production}

To establish whether the protective effects of WP were associated with inhibition of basal and tert-Butyl hydroperoxide ( $t$-BOOH)-induced ROS formation in SH-SY5Y cells, a fluorescent probe-mediated assay was done. In the basal state, pre-treatment with $10 \mu \mathrm{g} / \mathrm{mL}$ of WP induced a significant $(p<0.05)$ reduction in cellular ROS $(81 \%)$ generation compared to the control group 
(Figure 4). Regarding the effect of WP on the generation of ROS in a tert-butyl hydroperoxide $(t$-BOOH)-induced stimulus, pre-treatment with 5 and $10 \mu \mathrm{g} / \mathrm{mL}$ of powder significantly decreased ROS production (75\% and $69 \%$, respectively, with respect to the activated control). These results suggest that WP protects SH-SY5Y cells against induced oxidative damage.
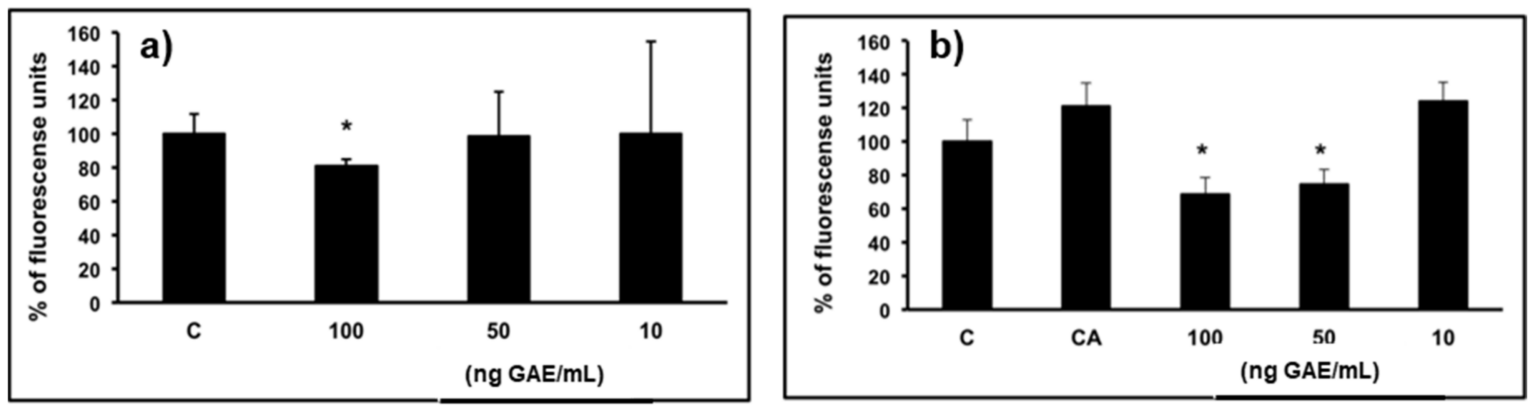

Figure 4. Protective effect of WP on intracellular ROS generation induced by $t$-BOOH treatment. SH-SY5Y cells were pretreated with increasing concentrations of WP (from 1 to $10 \mu \mathrm{g} / \mathrm{mL}$ ) corresponding to 10 to $100 \mathrm{ng}$ GAE/mL. Concentrations were expressed as ng gallic acid equivalent (GAE)/mL (9.86 ng GAE/ $\mu \mathrm{g} \mathrm{WP})$. Values are expressed as a percentage relative to the control conditions. (a) Represents basal state ( 0 min of $t$ - $\mathrm{BOOH}$ exposure) ${ }^{*} p<0.05$ compared to the control group. (b) Represents $t$ - $\mathrm{BOOH}$ activation (90 $\mathrm{min}$ of $t-\mathrm{BOOH}$ exposure). ${ }^{*} p<0.05$ compared to the control activated group.

\section{Discussion}

\subsection{Red Wine Powder (WP) Polyphenolic Composition}

Many authors have studied the polyphenolic composition of red wine from different grape varieties; however, very few studies exist on the actual composition of encapsulated red wine. In the present work, the presence of quercetin-3-glucuronide as one of the main flavonols should be noted (Table 1). Quercetin-3-glucuronide has already been detected in table grapes [24], although it is not so commonly found in European grape wine varieties or red wines. Additionally, the presence of syringetin-3-glucoside was found as one of the main flavonols in the WP, which is also somewhat peculiar for a Cabernet Sauvignon wine. This compound has only been reported, as far as we know, in Merlot and Sirah wines from Greece [25], and in different varieties of grapes used for "Vinho Verde" from Portugal [26]. Only a few authors have reported its presence in Cabernet Sauvignon grapes and wines from California [27].

Malvidin-3-glucoside represented $45 \%$ of total anthocyanins identified in the present analysis (Table 1). The encapsulated WP is also rich in flavanols; the monomers catechin and epicatechin and dimers B1 and B2 are especially abundant. Gallocatechin monomers and procyanidin trimers mainly formed by epicatechin and catechin units were observed. This is in accordance with the composition of most red wines [28].

In the WP, free anthocyanins in the form of 3-O-monoglucosides represent the predominant form within the Anthocyanins group (56\%). In other studies, with Vitis vinifera wines, similar conclusions have been reached [29,30]. In addition, there are other works with Cabernet Sauvignon wines that found that the content of malvidin-3-O-(6-O-acetyl)-glucoside is considerable for this varietal, and in the case of WP, represents $81.7 \%$ of the Anthocyanins-3-O-(6-O-acetyl)-glucoside group [31].

\subsection{Cell Viability}

It is known that hundreds of polyphenols are present in red wine. Thus, there is not any specific reason to include epicatechin in the activity trial besides of the fact that (-)-epicatechin is the main compound in the flavanols group (see Table 1). However, this polyphenol has been mentioned in 
the literature for its positive biological effects in cells [32]. In the case of (-)-epicatechin, a greater cellular survival can be observed at lower concentrations compared to WP. This behavior can be explained because the final balance of the effect of the powder is due to the joint action of the complex composition of the WP. In other words, it is the result of the synergies and/or antagonism effect between the different compounds.

The SH-SY5Y cell model has been chosen by some authors to study the neuro-biological effect of some polyphenols. For example, some of them have shown that resveratrol induced activation of the mitogen-activated protein kinases, extracellular-regulated kinases (ERK1 and ERK2), in human neuroblastoma SH-SY5Y cells; others proved the anti-apoptotic effect of trans-resveratrol on paclitaxel-induced apoptosis; on the other hand, some researchers elucidated a neuroprotective effect of resveratrol against $\beta$-Amyloid $(A \beta)$-induced neurotoxicity and showed that resveratrol protects SH-SY5Y neuroblastoma cells from apoptosis induced by dopamine. In addition to this, studies have found that quercetin 3-glucoside protected SH-SY5Y cells against hydrogen peroxide-induced oxidative stress and can also attenuate monoamine oxidase-A (MAO-A) activity in that cellular model. Finally, some authors have tested different polyphenol-derived metabolites in dopaminergic models against oxidative stress-induced cytotoxicity [21,33-40].

Most of these studies on SH-SY5Y models only tested some of the compounds present in red wine (mainly resveratrol or trans-resveratrol). However, wine is a complex mixture, and it is likely that a multitude of chemical constituents, as well as their metabolites, might work synergistically to impact human health $[41,42]$. For this reason, a WP obtained from whole red wine was utilized and showed the ability to protect against 6-OHDA-induced cell damage on SH-SY5Y neuronal cells.

\subsection{Effect of WP on Reactive Oxygen Species (ROS) Production}

Reactive oxygen and nitrogen species are considered major determinants of many degenerative diseases. ROS can act by damaging biological structures, but they can also affect cell signaling by changing the redox cellular status or by participating in intracellular signaling [43]. Although the mechanisms accountable for the death of dopaminergic cells (SH-SY5Y) are not completely understood, multiple pieces of evidence from human post-mortem investigations and animal studies indicate that oxidative stress is an important role in initiating this process [44].

It has been reported that ROS and RNS (Reactive Oxygen and Nitrogen species, respectively) are considered to act as pro-inflammatory signals in vivo by stimulating the activation of tumor necrosis factor (TNF-a), interleukin (IL) IL-1b and IL6 genes through activation of the redox-sensitive nuclear factor (NF-kB) [45]. In this way, the reduction of ROS would contribute to activate a decrease in the signaling cascade when a cellular system has been affected by some toxic component.

The neuroprotection exerted by WP can be explained through its antioxidant capacity (via ROS), a result that points in the same direction as the in vitro observations made by Rocha et al. and Galmarini et al., who found antioxidant power in wine powder using different methodologies (i.e., the chromogen radical 2,2-diphenyl-1-picrylhydrazyl $\left(\mathrm{DPPH}^{*}\right), \beta$-Carotene/Linoleic acid assay and change in ferric reducing capacity, FRAP method) $[19,20]$.

The results of the present work show that the WP has active redox properties in the neuronal model, which could help explain its action against the neurotoxicity induced by 6-OHDA. Overall, the results of this work can be explained by the combined effect resulting from the complex composition of red wine. Some studies have indicated that flavonols, in addition to their many other health benefits, contribute significantly to the protection of neuronal cells against oxidative-stress-induced neurotoxicity [46,47]. In Alzheimer's disease, neuronal loss is preceded by the extracellular accumulation of amyloid- $\beta$ peptide $(A \beta)$. It has been shown that pre-treatment of primary hippocampal cultures with quercetin significantly attenuates $A \beta$-induced toxicity, lipid peroxidation, protein oxidation and apoptosis $[46,47]$. A dose-response study indicated that quercetin exhibited protective capacities against $A \beta$-induced toxicity by modulating oxidative stress at lower doses [46,47]. In cerebral ischemia, calcium dysregulation is one of the main instigators of neuronal cell death 
and brain damage $[46,47]$. Catechin may protect against the brain injuries produced by endogenous neurotoxins involved in the onset of Parkinson's disease [46,47]. Catechin and epicatechin gallate have also shown an ability to suppress neuroinflammation and can attenuate and inhibit activation of microglia and/or astrocytes associated with the release of the mediators linked to the apoptotic death of neurons $[46,47]$. In addition, numerous studies indicate that catechin derivatives may delay the onset of neurodegenerative disorders such as Alzheimer's disease through numerous different mechanisms, including iron chelators, radical scavengers, and modulators of pro-survival genes [46,47].

\section{Materials and Methods}

Standard polyphenols for HPLC-MS-QTOF analysis (phloroglucinol, gallic acid, catechin, (-)-epicatechin, quercetin, quercetin-3-O-glucoside and resveratrol were obtained from Sigma-Aldrich (Madrid, Spain). Delphinidin-3-glucoside, cyanidin-3-glucoside, peonidin-3-glucoside and malvidin-3glucoside standards were obtained from Extrasynthese (Lyon, France), 6-OHDA, dichlorofluorescin (DCFH) and Dulbecco's Phosphate Buffered Saline were purchased from Sigma-Aldrich Quimica S.A. (Madrid, Spain). HPLC-grade solvents were purchased from Merck (Darmstadt, Germany). Dulbecco Modified Eagle Medium (DMEM), fetal bovine serum (FBS), penicillin/streptomycin, trypsin and L-glutamine were purchased from Lonza (Barcelona, Spain). Dimethyl sulfoxide (DMSO) was obtained from Panreac (Barcelona, Spain). Cell culture dishes were obtained from BD Falcon (Madrid, Spain).

The wine used was a commercial Cabernet Sauvignon, "Postales del Fin del Mundo" from Neuquén province, Argentina. Its alcohol content was $13.7 \%$ and its $\mathrm{pH}$ 3.6. Total polyphenol content was $2230 \pm 160 \mathrm{mg} \mathrm{GAE} / \mathrm{L}$ as determined by the Folin-Ciocalteau method [23]. The carbohydrates used for encapsulation were maltodextrin dextrose equivalent $10\left(\mathrm{MD}_{10}\right)$ from Productos de Maíz, S.A., Argentina and gum arabic (from Gelfix, Buenos Aires, Argentina).

\subsection{Encapsulation Procedure}

In the present work, the encapsulation procedure described in previous works was followed [22]. A mixture of $\mathrm{MD}_{10}$ and gum arabic (65:35) was dissolved (9\% total weight in red wine). The wine with dissolved encapsulating agents was poured into an aluminum tray (depth of sample, $1 \mathrm{~cm}$ ), frozen and freeze dried. The freeze-drying process was performed using a laboratory-scale FIC148 LI-I-E300-CRT freeze dryer (Rificor, Buenos Aires, Argentina) operated with a freezing plate and condenser at $-40{ }^{\circ} \mathrm{C}$ and at a vacuum of $100 \mu \mathrm{m} \mathrm{Hg}$ for $40 \mathrm{~h}$ at room temperature. Temperature of the dry layer did not exceed $25^{\circ} \mathrm{C}$.

\subsection{HPLC-QTOF Analysis}

Samples were prepared by weighting $50 \mathrm{mg}$ of WP in methanol:water (1:3) containing formic acid at $0.1 \%$. Prior to injection samples were filtered through a syringe filter $(0.45 \mu \mathrm{m})$. Quantitative analysis of phenolic compounds was performed using an Agilent 1200 series liquid chromatographic system equipped with a quaternary pump, thermostatic autosampler, thermostated column compartment, and diode-array detector (DAD). High performance liquid chromatography coupled to quadrupole time-of-flight mass analyzer (HPLC-QTOF) with an electrospray ionization source (ESI) Jetstream technology was used. The spectra were recorded in negative and positive ion mode and the MS detector was programmed to perform a consecutive scan series: extended dynamic range, low $1700 \mathrm{~m} / z$. A $5 \mu \mathrm{L}$ aliquot of sample was injected and analyzed in a Phenomenex Luna C18 column $(150 \times 4.6 \mathrm{~mm}, 3 \mu \mathrm{m})$. Two solvents were used during the analysis. Solvent A was composed of distilled water/formic acid (FA) $(0.1 \%$ FA) and solvent B consisted of acetonitrile with formic acid (ACN/FA) (0.1\% FA). A constant

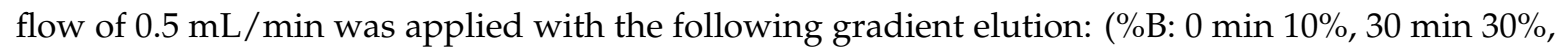
$35 \mathrm{~min} 35 \%$, $40 \mathrm{~min} 45 \%$, $50 \mathrm{~min} \mathrm{10 \% ).} \mathrm{The} \mathrm{identification} \mathrm{of} \mathrm{compounds} \mathrm{was} \mathrm{done} \mathrm{by} \mathrm{comparing}$ spectral characteristics of sample compounds, as well as by fragmentation, and comparison of the obtained fragments with the literature data. Standards of polyphenolic compounds were also injected 
to help in the identifications. An Agilent Mass Hunter Workstation was used for data acquisition and processing.

\subsection{Cell Culture and Viability}

SH-SY5Y human neuroblastoma cells were seeded and cultured regularly in DMEM containing $4.5 \mathrm{~g} / \mathrm{L}$ glucose-584 mg/L L-glutamine and supplemented with $10 \%$ fetal bovine serum (FBS) and $1 \%$ penicillin/streptomycin $(5000 \mathrm{U} / \mathrm{mL})$. Cells were plated in $75 \mathrm{~cm}^{2}$ tissue culture flasks and maintained at $37^{\circ} \mathrm{C}$ under $5 \% \mathrm{CO}_{2}$ in a humidifier incubator until $80-90 \%$ confluence was reached. Medium was changed to serum-free medium $24 \mathrm{~h}$ prior to testing. Cells were harvested with trypsin-EDTA. SH-SY5Y cells were seeded in 96-well plates for the cytotoxicity test and cellular viability post 6-OHDA treatment $\left(1 \times 10^{4}\right.$ cells per well), in 24 -well plates for the ROS assay $\left(1 \times 10^{5}\right.$ cells per well), and 6-well plates for the Nitric Oxide $(\mathrm{NO})$ measurement $\left(1 \times 10^{6}\right.$ cells per well).

SH-SY5Y cell viability was assessed by the (3-(4,5-dimethylthiazol-2-yl)-2,5-diphenyltetrazolium bromide) MTT reduction assay. Cell viability after WP and epicatechin pre-treatment was studied as follows. After $24 \mathrm{~h}$ of SH-SY5Y cell incubation (96-plate well), medium was replaced with serum-free medium containing different concentrations of WP $\left(1 \times 10^{-3}-200 \mathrm{mg}\right.$ powder $\left./ \mathrm{mL}\right)$ and (-)-epicatechin compound (10-200 $\mu \mathrm{M}$, dissolved in dimethyl sulfoxide (DMSO), $0.1 \%$ final concentration) and then cells were incubated at $37^{\circ} \mathrm{C}$ under $5 \% \mathrm{CO}_{2}$ for $24 \mathrm{~h}$. For all concentrations of WP, controls of encapsulating agents (MD10 and Arabic gum) were made. Control cells without treatment were incubated in serum-free medium without and with $0.1 \%$ DMSO for WP and (-)-epicatechin, respectively.

For cell viability after 6-OHDA treatment, cell medium was replaced (after $24 \mathrm{~h}$ ) with serum-free medium containing different concentrations of 6-OHDA (25-250 $\mu \mathrm{M}$ dissolved in $0.02 \%$ ascorbic acid-PBS solution) and incubated at $37^{\circ} \mathrm{C}$ under $5 \% \mathrm{CO}_{2}$ for an additional $24 \mathrm{~h}$ (control cells were treated only with $0.02 \%$ ascorbic acid-PBS solution).

For cell viability after co-treatment with WP or epicatechin with 6-OHDA, cell medium (after $24 \mathrm{~h}$ ) was replaced with serum-free medium containing: (a) different concentrations of WP $\left(1 \times 10^{-3}-200 \mathrm{mg}\right.$ powder $/ \mathrm{mL}$ ), together with $150 \mu \mathrm{M}$ of 6-OHDA or (b) different concentrations (-)-epicatechin (10-200 $\mu \mathrm{M}$, dissolved in DMSO, $0.1 \%$ final concentration), together with $150 \mu \mathrm{M}$ of 6 -OHDA of 6-OHDA. The SH-SY5Y cells were incubated at $37{ }^{\circ} \mathrm{C}$ under $5 \% \mathrm{CO}_{2}$ for another additional $24 \mathrm{~h}$. Control cell samples were incubated in serum-free medium without and with $0.1 \%$ DMSO for WP and (-)-epicatechin, respectively and $0.02 \%$ ascorbic acid-PBS solution.

Thereafter, $20 \mu \mathrm{L}$ of a MTT solution in PBS $(5 \mathrm{mg} / \mathrm{mL})$ were added to each well for the quantification of the living metabolically active cells after $2 \mathrm{~h}$ incubation. Then, formazan crystals in the wells were solubilized in $200 \mu \mathrm{L}$ DMSO. Absorbance was measured at a wavelength of $570 \mathrm{~nm}$ employing a microplate reader PowerWave ${ }^{\mathrm{TM}}$ XS (BioTek Instruments, Inc., Winooski, VT, USA). The viability was calculated assuming that the controls for each respective test were $100 \%$ viable.

\subsection{Evaluation of Reactive Oxygen Species (ROS) Generation}

Intracellular ROS levels were quantified following a previously described method [48] with some modifications. SH-SY5Y cells were seeded in 24 -well plates until they reached $80 \%$ confluence. Then, the cells were treated with different concentrations of WP $(1-10 \mu \mathrm{g} \mathrm{WP} / \mathrm{mL}) .24 \mathrm{~h}$ later, cells were washed with PBS and incubated with the culture medium and Dichloro-dihydro-fluorescein diacetate (DCFH-DA) probe for $30 \mathrm{~min}$. Finally, plates were measured at two times: (a) Basal state: $0 \mathrm{~min}$ of $t$ - $\mathrm{BOOH}$ exposure, and (b) $t$ - $\mathrm{BOOH}$ activated state: $90 \mathrm{~min}$ of $t-\mathrm{BOOH}$ exposure. Measurements were made in a fluorescent microplate reader at an excitation wavelength of $485 \mathrm{~nm}$ and an emission wavelength of $530 \mathrm{~nm}$ (Bio-Tek, Swindon, UK). 


\subsection{Statistical Analysis}

All the experiments were carried out in triplicate, and results are expressed as mean \pm standard deviation. Results were analyzed by one-way analysis of variance (ANOVA) test using InfoStat v.2013 (Universidad Nacional de Cordoba, Argentina). Means comparisons among storage time were carried out by Tukey's test at $p<0.05$.

\section{Conclusions}

The polyphenol profile of a freeze-dried encapsulated red wine powder was determined using HPLC-QTOF analysis. Thirty-five polyphenols were identified, including anthocyanins, flavonols, flavanols, phenolic acids and stilbenoids. These results showed a rich and complex polyphenolic composition in the de-alcoholized/encapsulated red wine. The present study suggest that red wine powder exerts a neuroprotective effect against 6-OHDA-induced damage that can be explained by the action of wine polyphenols through an antioxidant mechanism as verified by performing ROS analysis.

Acknowledgments: We are grateful to the Analysis Service Unit facilities of ICTAN for the analysis of Chromatography and Mass Spectrometry, especially to Inma Alvarez for her assistance. We want to thank EMHE "Enhancing Mobility between Latin-American and Caribbean countries and Europe" Program at CSIC for grant MHE-200007 and Ministerio de Economía, Industria y Competitividad for grant AGL2016-76832-R.

Author Contributions: D.R.-P., J.C., C.Z. and S.P.T. conceived and designed the experiments; D.R.-P. and S.P.-T. performed the experiments; D.R.-P. and S.P.-T. analyzed the data; D.R.-P., J.C., C.Z. and S.P.-T. wrote the paper.

Conflicts of Interest: The authors declare no conflict of interest.

\section{References}

1. Stevenson, D.E.; Hurst, R.D. Polyphenolic phytochemicals-Just antioxidants or much more? Cell. Mol. Life Sci. 2007, 64, 2900-2916. [CrossRef] [PubMed]

2. Cendrowski, A.; Ścibisz, I.; Kieliszek, M.; Kolniak-Ostek, J.; Mitek, M. UPLC-PDA-Q/TOF-MS profile of polyphenolic compounds of liqueurs from Rose petals (Rosa rugosa). Molecules 2017, 22, 1832. [CrossRef] [PubMed]

3. Cendrowski, A.; Ścibisz, I.; Mitek, M.; Kieliszek, M.; Kolniak-Ostek, J. Profile of the Phenolic Compounds of Rosa rugosa Petals. J. Food Qual. 2017. [CrossRef]

4. Garcia-Alonso, M.; Rimbach, G.; Rivas-Gonzalo, J.C.; de Pascual-Teresa, S. Antioxidant and cellular activities of anthocyanins and their corresponding vitisins A-Studies in platelets, monocytes, and human endothelial cells. J. Agric. Food. Chem. 2004, 52, 3378-3384. [CrossRef] [PubMed]

5. Sun, A.Y.; Simonyi, A.Ñ.; Sun, G.Y. The 'French Paradox' and beyond: Neuroprotective effects of polyphenols. Free Radic. Biol. Med. 2002, 32, 314-318. [CrossRef]

6. Corder, R.; Mullen, W.; Khan, N.Q.; Marks, S.C.; Wood, E.G.; Carrier, M.J.; Crozier, A. Oenology: Red wine procyanidins and vascular health. Nature 2006, 444, 566. [CrossRef] [PubMed]

7. Jiménez, A.; Lisa-Santamaría, P.; García-Marino, M.; Escribano-Bailón, M.T.; Rivas-Gonzalo, J.C.; Revuelta, J.L. The biological activity of the wine anthocyanins delphinidin and petunidin is mediated through Msn2 and Msn4 in Saccharomyces cerevisiae. FEMS Yeast Res. 2010, 10, 858-869. [CrossRef] [PubMed]

8. German, J.B.; Walzem, R.L. The health benefits of wine. Annu. Rev. Nutr. 2000, 20, 561-593. [CrossRef] [PubMed]

9. Renaud, S.; de Lorgeril, M. Wine, alcohol, platelets, and the French paradox for coronary heart disease. Lancet 1992, 339, 1523-1526. [CrossRef]

10. Nikfardjam, M.S.P.; Márk, L.; Avar, P.; Figler, M.; Ohmacht, R. Polyphenols, anthocyanins, and trans-resveratrol in red wines from the Hungarian Villány region. Food Chem. 2006, 98, 453-462. [CrossRef]

11. Soulat, T.; Philippe, C.; Sollier, C.B.D.; Brezillon, C.; Berge, N.; Teissedre, P.L.; Drouet, L. Wine constituents inhibit thrombosis but not atherogenesis in C57BL/6 apolipoprotein E-deficient mice. Br. J. Nutr. 2006, 96, 290. [CrossRef] [PubMed] 
12. Gorelik, S.; Ligumsky, M.; Kohen, R.; Kanner, J. A novel function of red wine polyphenols in humans: prevention of absorption of cytotoxic lipid peroxidation products. FASEB J. 2008, 22, 41-46. [CrossRef] [PubMed]

13. Carollo, C.; Presti, R.; Caimi, G. Wine, diet, and arterial hypertension. Angiology 2007, 58, 92-96. [CrossRef] [PubMed]

14. Karatzi, K.N.; Papamichael, C.M.; Karatzis, E.N.; Papaioannou, T.G.; Aznaouridis, K.A.; Katsichti, P.P.; Mavrikakis, M.E. Red wine acutely induces favorable effects on wave reflections and central pressures in coronary artery disease patients. Am. J. Hypertens. 2005, 18, 1161-1167. [CrossRef] [PubMed]

15. Pérez-Jiménez, J.; Serrano, J.; Tabernero, M.; Arranz, S.; Díaz-Rubio, M.E.; García-Diaz, L.; Saura-Calixto, F. Effects of grape antioxidant dietary fiber in cardiovascular disease risk factors. Nutrition 2008, 24, 646-653. [CrossRef] [PubMed]

16. Greenrod, W.; Stockley, C.S.; Burcham, P.; Abbey, M.; Fenech, M. Moderate acute intake of de-alcoholised red wine, but not alcohol, is protective against radiation-induced DNA damage ex vivo-Results of a comparative in vivo intervention study in younger men. Mutat. Res. 2005, 591, 290-301. [CrossRef] [PubMed]

17. Lecour, S.; Blackhurst, D.; Marais, D.; Opie, L. Lowering the degree of alcohol in red wine does not alter its cardioprotective effect. J. Mol. Cell. Cardiol. 2006, 40, 997-998. [CrossRef]

18. Sanchez, V.; Baeza, R.; Galmarini, M.V.; Zamora, M.C.; Chirife, J. Freeze-Drying Encapsulation of Red Wine Polyphenols in an Amorphous Matrix of Maltodextrin. Food Bioprocess Technol. 2013, 6, 1350-1354. [CrossRef]

19. Rocha-Parra, D.F.; Lanari, M.C.; Zamora, M.C.; Chirife, J. Influence of storage conditions on phenolic compounds stability, antioxidant capacity and colour of freeze-dried encapsulated red wine. LWT Food Sci. Technol. 2006, 70, 162-170. [CrossRef]

20. Galmarini, M.V.; Maury, C.; Mehinagic, E.; Sanchez, V.; Baeza, R.I.; Mignot, S.; Zamora, C.; Chirife, J. Stability of Individual Phenolic Compounds and Antioxidant Activity During Storage of a Red Wine Powder. Food Bioprocess Technol. 2013, 6, 3585-3595. [CrossRef]

21. Nicolini, G.; Rigolio, R.; Miloso, M.; Bertelli, A.A.E.; Tredici, G. Anti-apoptotic effect of trans-resveratrol on paclitaxel-induced apoptosis in the human neuroblastoma SH-SY5Y cell line. Neurosci. Lett. 2001, 302, 41-44. [CrossRef]

22. Cavallini, G.; Straniero, S.; Donati, A.; Bergamini, E. Resveratrol requires red wine polyphenols for optimum antioxidant activity. J. Nutr. Health Aging 2016, 20, 540-545. [CrossRef] [PubMed]

23. Singleton, V.L.; Rossi, J.A., Jr. Colorimetry of total phenolics with phosphomolybdic-phosphotungtic acid reagent. Am. J. Enol. Vitic. 1965, 16, 144-158.

24. Cantos, E.; García-Viguera, C.; de Pascual-Teresa, S.; Tomás-Barberán, F.A. Effect of postharvest ultraviolet irradiation on resveratrol and other phenolics of cv. Napoleon table grapes. J. Agric. Food. Chem. 2000, 10, 4606-4612. [CrossRef]

25. Bimpilas, A.; Tsimogiannis, D.; Balta-Brouma, K.; Lymperopoulou, T.; Oreopoulou, V. Evolution of phenolic compounds and metal content of wine during alcoholic fermentation and storage. Food Chem. 2015, 178, 164-171. [CrossRef] [PubMed]

26. Dopico-García, M.S.; Fique, A.; Guerra, L.; Afonso, J.M.; Pereira, O.; Valentão, P.; Seabra, R.M. Principal components of phenolics to characterize red Vinho Verde grapes: Anthocyanins or non-coloured compounds? Talanta 2008, 75, 1190-1202. [CrossRef] [PubMed]

27. Wang, H.; Race, E.J.; Shrikhande, A.J. Anthocyanin transformation in Cabernet Sauvignon wine during aging. J. Agric. Food Chem. 2003, 51, 7989-7994. [CrossRef] [PubMed]

28. De Pascual-Teresa, S.; Rivas-Gonzalo, J.C.; Santos-Buelga, C. Prodelphinidins and related flavanols in wine. International. J. Food Sci. Technol. 2000, 35, 33-40. [CrossRef]

29. He, F.; Liang, N.N.; Mu, L.; Pan, Q.H.; Wang, J.; Reeves, M.J.; Duan, C.Q. Anthocyanins and their variation in red wines I. Monomeric anthocyanins and their color expression. Molecules 2012, 17, 1571-1601. [CrossRef] [PubMed]

30. Li, S.Y.; He, F.; Zhu, B.Q.; Wang, J.; Duan, C.Q. Comparison of Phenolic and Chromatic Characteristics of Dry Red Wines Made from Native Chinese Grape Species and Vitis Vinifera. Int. J. Food Prop. 2017, 20, 2134-2146. [CrossRef]

31. Shi, P.B.; Yue, T.X.; Ai, L.L.; Cheng, Y.F.; Meng, J.F.; Li, M.H.; Zhang, Z.W. Phenolic compound profiles in grape skins of Cabernet Sauvignon, Merlot, Syrah and Marselan cultivated in the Shacheng Area (China). S. Afr. J. Enol. Vitic. 2016, 37, 132-138. 
32. Shay, J.; Elbaz, H.A.; Lee, I.; Zielske, S.P.; Malek, M.H.; Hüttemann, M. Molecular Mechanisms and Therapeutic Effects of (-)-Epicatechin and Other Polyphenols in Cancer, Inflammation, Diabetes, and Neurodegeneration. Oxid. Med. Cell. Longev. 2015. [CrossRef] [PubMed]

33. Miloso, M.; Bertelli, A.A.E.; Nicolini, G.; Tredici, G. Resveratrol-induced activation of the mitogen-activated protein kinases, ERK1 and ERK2, in human neuroblastoma SH-SY5Y cells. Neurosci. Lett. 1999, 264, 141-144. [CrossRef]

34. Tredici, G.; Miloso, M.; Nicolini, G.; Galbiati, S.; Cavaletti, G.; Bertelli, A. Resveratrol, map kinases and neuronal cells: Might wine be a neuroprotectant? Drugs Exp. Clin. Res. 1999, 25, 99-103. [PubMed]

35. Savaskan, E.; Olivieri, G.; Meier, F.; Seifritz, E.; Wirz-Justice, A.; Müller-Spahn, F. Red wine ingredient resveratrol protects from $\beta$-amyloid neurotoxicity. Gerontology 2003, 49, 380-383. [CrossRef] [PubMed]

36. Lee, M.K.; Kang, S.J.; Poncz, M.; Song, K.-J.; Park, K.S. Resveratrol protects SH-SY5Y neuroblastoma cells from apoptosis induced by dopamine. Exp. Mol. Med. 2007, 39, 376-384. [CrossRef] [PubMed]

37. Soundararajan, R.; Wishart, A.D.; Rupasinghe, H.P.V.; Arcellana-Panlilio, M.; Nelson, C.M.; Mayne, M.; Robertson, G.S. Quercetin 3-glucoside protects neuroblastoma (SH-SY5Y) cells in vitro against oxidative damage by inducing sterol regulatory element-binding protein-2-mediated cholesterol biosynthesis. J. Biol. Chem. 2008, 283, 2231-2245. [CrossRef] [PubMed]

38. Bandaruk, Y.; Mukai, R.; Terao, J. Cellular uptake of quercetin and luteolin and their effects on monoamine oxidase-A in human neuroblastoma SH-SY5Y cells. Toxicol. Rep. 2014, 1, 639-649. [CrossRef] [PubMed]

39. González-Sarrías, A.; Núñez-Sánchez, M.Á.; Tomás-Barberán, F.A.; Espín, J.C. Neuroprotective effects of bioavailable polyphenol-derived metabolites against oxidative stress-induced cytotoxicity in human neuroblastoma SH-SY5Y cells. J. Agric. Food Chem. 2016, 65, 752-758. [CrossRef] [PubMed]

40. Esteban-Fernández, A.; Rendeiro, C.; Spencer, J.P.E.; Gigorro del Coso, D.; González del Llano, M.D.; Bartolomé, B.; Moreno-Arribas, M.V. Neuroprotective Effects of Selected Microbial-Derived Phenolic Metabolites and Aroma Compounds from Wine in Human SH-SY5Y Neuroblastoma Cells and Their Putative Mechanisms of Action. Front. Nutr. 2017, 4, 3. [CrossRef] [PubMed]

41. Pignatelli, P.; Ghiselli, A.; Buchetti, B.; Carnevale, R.; Natella, F.; Germanò, G.; Violi, F. Polyphenols synergistically inhibit oxidative stress in subjects given red and white wine. Atherosclerosis 2006, 188, 77-83. [CrossRef] [PubMed]

42. Guilford, J.M.; Pezzuto, J.M. Wine and health: A review. Am. J. Enol. Vitic. 2011, 62, 471-486. [CrossRef]

43. Giovinazzo, G.; Grieco, F. Functional Properties of Grape and Wine Polyphenols. Plant Foods Hum. Nutr. 2015, 70, 454-462. [CrossRef] [PubMed]

44. Tseng, W.T.; Hsu, Y.W.; Pan, T.M. The ameliorative effect of Monascus purpureus NTU 568-fermented rice extracts on 6-hydroxydopamine-induced neurotoxicity in SH-SY5Y cells and the rat model of Parkinson's disease. Food Funct. 2016, 7, 752-762. [CrossRef] [PubMed]

45. Rabelo, T.K.; Zeidán-Chuliá, F.; Vasques, L.M.; dos Santos, J.P.; da Rocha, R.F.; Pasquali, M.A.; Rybarczyk-Filho, J.L.; Araújo, A.A.; Moreira, J.C.; Gelain, D.P. Redox characterization of usnic acid and its cytotoxic effect on human neuron-like cells (SH-SY5Y). Toxicol. In Vitro 2012, 26, 304-314. [CrossRef] [PubMed]

46. Basli, A.; Soulet, S.; Chaher, N.; Mérillon, J.-M.; Chibane, M.; Monti, J.-P.; Richard, T. Wine Polyphenols: Potential Agents in Neuroprotection. Oxid. Med. Cell. Longev. 2012, 805762. [CrossRef] [PubMed]

47. Caruana, M.; Cauchi, R.; Vassallo, N. Putative Role of Red Wine Polyphenols against Brain Pathology in Alzheimer's and Parkinson's Disease. Front. Nutr. 2016, 3, 31. [CrossRef] [PubMed]

48. Silván, J.M.; Reguero, M.; de Pascual-Teresa, S. A protective effect of anthocyanins and xanthophylls on UVB-induced damage in retinal pigment epithelial cells. Food Funct. 2016, 7, 1067-1076. [CrossRef] [PubMed]

Sample Availability: Samples of the compounds are available from the authors. 